\title{
CORP-2 trial and the role of colchicine in nonidiopathic pericarditis
}

Lovely Chhabra, Kirandeep Dua and David H. Spodick

We read with great interest the News \& Views article by Syed and Mayosi (Pharmacotherapy: Colchicine for recurrent pericarditis-what's new in CORP-2? Nat. Rev. Cardiol. doi:10.1038/nrcardio.2014.71), ${ }^{1}$ which provided an excellent overview of the randomized controlled CORP-2 trial, ${ }^{2}$ and focused on the role of colchicine in recurrent pericarditis. The authors pointed out that patients with nonidiopathic pericarditis received little benefit from colchicine in the trial. However, we would like to emphasize that the CORP-2 trial analysis was not prespecified for these benefits or observations, and the subgroups of patients with nonidiopathic pericarditis (such as those with postcardiac injury syndromes, autoimmune disorders, or connective tissue diseases) had too few patients to draw definitive conclusions. ${ }^{2}$ Nevertheless, the CORP-2 study ${ }^{2}$ showed a $>10 \%$ reduction in the recurrence of pericarditis in patients treated with colchicine. This reduction is perhaps a substantial benefit and might be significant in a larger-sized prospective study.

Until further studies are available to suggest otherwise, the routine use of colchicine in combination with other standard therapies for nonidiopathic pericarditis might be a reasonable treatment for these patients. In our own routine practice, we often use a combination therapy of steroids and colchicine for treating patients with autoimmune pericarditis. In our experience, these patients often have better outcomes than those individuals treated with steroids alone. Steroids are often used to treat patients with autoimmune pericarditis or underlying connective tissue diseases. ${ }^{3-4}$

One aspect of the pericardial disease that remains frustrating, for both clinicians and patients, is multiple recurrences of the disease, which often lead to incessant or refractory pericarditis. In the CORP-2 trial, ${ }^{2} \geq 22 \%$ of patients experienced recurrent pericarditis despite taking colchicine for 6 months. ${ }^{2}$ Although this percentage is approximately half that of patients who were not treated with colchicine, the number is still alarmingly high. A multidrug approach is often used in these patients, which includes the combination of NSAIDs, colchicine, and steroids. ${ }^{5}$ Despite this treatment, a large subgroup of patients with recurrent pericarditis might experience debilitating repeating symptoms, and improved pharmaceutical alternatives are, therefore, required. Anecdotal reports suggest that interleukin-1 inhibitors might be useful in patients with recurrent pericarditis. ${ }^{5} \mathrm{~A}$ small, prospective study in a paediatric population indicated that anakinra can significantly improve the symptoms of patients with refractory pericarditis. ${ }^{6}$ Large, prospective studies are needed to explore the benefit of anakinra and other interleukin inhibitors in adult patients with refractory or recurrent pericarditis. Such future studies will help to formulate standardized treatment strategies.
Department of Cardiovascular Medicine, Hartford Hospital, University of Connecticut School of Medicine, 80 Seymour Street, Hartford, CT 06102, USA (L.C.). Saint Vincent Hospital, University of Massachusetts Medical School, 123 Summer Street, Worcester, MA 01608, USA (K.D., D.H.S.).

Correspondence to: L.C. lovids@hotmail.com

Competing interests

D.H.S. receives royalties as author of The Pericardium: a Comprehensive Textbook (Marcel Dekker, 1997). The other authors declare no competing interests.

1. Syed, F. F. \& Mayosi, B. M. Colchicine for recurrent pericarditis-what's new in CORP-2? Nat. Rev. Cardiol. http://dx.doi.org/10.1038/ nrcardio.2014.71.

2. Imazio, M. et al. Efficacy and safety of colchicine for treatment of multiple recurrences of pericarditis (CORP-2): a multicentre, double-blind, placebo-controlled, randomised trial. Lancet http://dx.doi.org/10.1016/ S0140-6736(13)62709-9.

3. Spodick, D. H. in The Pericardium: a Comprehensive Textbook 314-333 (Marcel Dekker, 1997).

4. Chhabra, L. \& Spodick, D. H. Letter by Chhabra and Spodick regarding article, "Treatment of acute and recurrent idiopathic pericarditis". Circulation 128, e391 (2013).

5. Chhabra, L., Khalid, N. \& Spodick, D. H. Recurrent pericarditis: can anakinra offer a promising therapy in adults with refractory symptoms? Rev. Esp. Cardiol. (in press).

6. Finetti, M. et al. Long-term efficacy of interleukin-1 receptor antagonist (anakinra) in corticosteroid-dependent and colchicineresistant recurrent pericarditis. J. Pediatr. 164, 1425-1431.e1 (2014). 